\title{
The role of partner characteristics in attachment insecurity and depressive symptoms
}

\author{
VALERIE E. WHIFFEN \\ University of Ottawa, Canada
}

\begin{abstract}
Depression is associated with marital distress and attachment insecurity in romantic relationships. In this article, I propose an attachment-theory model of depression, which links the characteristics of romantic partners to attachment insecurity and depression. I hypothesized that individuals who are avoidant of closeness and/or who devalue their spouses will be perceived as unresponsive to their spouses' vulnerability, which will increase the spouse's attachment insecurity. Attachment insecurity was then proposed to contribute to depressive symptoms over time. A sample of married or cohabiting couples was recruited to complete questionnaires at an Internet Web site at 2 time points, approximately 3 months apart. Path analysis showed that for both husbands $(N=82)$ and wives $(N=99)$, avoidance of closeness in 1 partner was associated with perceived unresponsiveness to vulnerability and attachment insecurity in the other partner. In addition, for husbands, attachment insecurity at T1 predicted depressive symptoms at T2, above and beyond baseline levels of depression. These results provide encouraging support for an attachment-theory approach to the study and treatment of depression, particularly among married or cohabiting men.
\end{abstract}

According to attachment theory (Bowlby, 1969, 1973, 1980), children learn that they are lovable and that significant others are reliable and responsive to their emotional needs by having attachment figures that are warm, interested in, and responsive to them. In contrast, children who experience rejection or inconsistency in their relationships with caregivers develop working models of themselves as unlovable and undeserving of care, and working models of others as hostile and rejecting or unreliable and untrustworthy. Hazan and Shaver (1987) were the first researchers to propose that similar processes operate in adult romantic relationships. Their conceptualization, along with Bartholomew's (1990) important elaboration, has produced a wealth of research in the past 15 years.

Two orthogonal dimensions underlie attachment in romantic relationships: anxiety about attachment figures and avoidance of

Correspondence should be addressed to Valerie E. Whiffen, University of Ottawa, School of Psychology, Ottawa, ON K1N 6N5, Canada, e-mail: whiff@uottawa.ca. closeness (e.g., Brennan, Clark, \& Shaver, 1998; Griffin \& Bartholomew, 1994a; Simpson, 1990). The first dimension, which is roughly equivalent to Bowlby's working model of self, reflects fears that one is unlovable and that rejection or abandonment by romantic partners is possible. The second dimension parallels Bowlby's working model of others and reflects the extent to which individuals prefer to maintain emotional distance and autonomy in close relationships. Crossing the two dimensions creates the four attachment prototypes that dominated early research (Brennan et al., 1998). Individuals who are securely attached have positive working models of both self and others. They believe that they are lovable and that significant others will be available and emotionally responsive to them when needed. Preoccupied individuals have a negative working model of self and a positive model of others. They seek reassurance from attachment figures because they feel unlovable, and they are vigilant to signs that they might be abandoned. Individuals who are fearful-avoidant have negative working models of both self and others. They want to 
be close to attachment figures but believe that rejection is inevitable, a dilemma that they resolve by maintaining emotional distance even in close relationships. Finally, dismissing individuals have a negative working model of others but a positive model of self. They protect their self-esteem from potentially rejecting interactions with attachment figures by discounting the importance of attachment relationships.

Adult attachment theory has been used extensively to study close relationships and now is being applied to the conceptualization and treatment of clinical problems (Johnson \& Whiffen, 2003). For instance, researchers propose that attachment insecurity is a risk factor for depression, particularly in the context of life transitions and interpersonal stress (Anderson, Beach, \& Kaslow, 1999; Hammen et al., 1995; Ingram, Miranda, \& Segal, 1998; Whiffen \& Johnson, 1998). Basic research confirms a link between adult attachment and depression. In both clinical and nonclinical samples, depression is consistently correlated with anxiety about attachment figures in studies using dimensional measures of attachment, and with the fearful and anxious prototypes in studies using the categorical system (e.g., Carnelley, Pietromonaco, \& Jaffe, 1994; Cyranowski et al., 2002; Roberts, Gotlib, \& Kassel, 1996; Whiffen, Kallos-Lilly, \& MacDonald, 2001). Furthermore, recovered depressed persons report elevated rates of fearful and anxious attachment relative to individuals without a history of depression (Haaga et al., 2002). Thus, depressed persons' attachment anxiety does not appear to be attributable to depressed mood.

There is a clear connection between attachment insecurity and marital distress. Insecurely attached individuals are less satisfied with their marriages (e.g., Kobak \& Hazan, 1991), and they show a variety of emotional and cognitive processing biases that are likely to disrupt the harmony of their marriages and to interfere with the process of relationship repair when problems occur (Johnson \& Whiffen, 1999). For instance, they have difficulty providing support to their partners under stressful circumstances (Feeney \& Collins, 2001; Fraley \& Shaver, 1998; Simpson, Rholes, \& Nelligan, 1992), they experience more anger in interpersonal situations (Mikulincer, 1998), and they attempt to resolve conflict in ways that are likely to exacerbate interpersonal problems (Simpson, Rholes, \& Phillips, 1996).

Depression also is strongly associated with marital distress, for both men and women (Whisman, 2001). Marital distress substantially increases the risk of an episode of depression (Whisman \& Bruce, 1999) and predicts relapse after recovery (Hooley \& Teasdale, 1989). A cross-sectional study by Scott and Cordova (2002) indicated that marital distress and depressive symptoms are correlated only when individuals are insecurely attached. In a community sample of couples, there was no correlation between marital distress and depression for either husbands or wives who rated themselves low on the anxious prototype; however, the correlation was significant for individuals who rated themselves high on this prototype.

Attachment security usually is conceptualized as an intrapersonal variable. However, models of self and other summarize real interactions with real attachment figures; they can be thought of as "relational schemas" that capture the essence of real world interpersonal relations (Baldwin, 1992). I propose that attachment insecurity among married or cohabiting individuals stems at least in part from real interactions with romantic partners and spouses. Spouses who are warm and emotionally available mirror an image of the self as lovable and worthy, while spouses who are cold, hostile, critical, or disengaged reflect back a picture of the self as unlovable, defective, or unworthy of care. Feedback from one's spouse that one is unlovable is inherently demoralizing. Thus, I propose that real interactions with spouses help to create and/or to confirm the negative working models of self that are linked to depression.

Bowlby (1980) suggested that when individuals feel afraid, stressed, or vulnerable, they appraise their attachment figures for signs that they are emotionally available and likely to respond in ways that will be comforting and reassuring. A comforting attachment figure helps the individual to regulate negative affect. I propose that perceived partner unresponsiveness is based in part on the real characteristics of partners. Spouses may be unresponsive to their partners' vulnerability for one of two 
reasons. First, they may be avoidant of closeness. Avoidant people tend to be critical, irritable, and distancing when their partners are in need of support (Campbell, Simpson, Kashy, $\&$ Rholes, 2001). They tend not to be attuned to emotions (Mikulincer, Florian, \& Weller, 1993), and to have difficulty giving support (Fraley \& Shaver, 1998; Simpson et al., 1992), in part because they lack empathy for others (Feeney \& Collins, 2001). Thus, avoidant individuals may feel uncomfortable with vulnerable feelings and have difficulty knowing how to respond when their partners express these feelings. Partner avoidance of closeness could lead to a perception of the partner as unresponsive, which may increase the risk of depression.

The results of three previous studies are consistent with this hypothesis. The first was a study of caregiving in a sample of dating university couples who were placed in a mildly stressful situation (Collins \& Feeney, 2000). Good-quality caregiving was defined as being attentive and understanding, without communicating blame or attempting to avoid the discussion of issues. The results showed that good-quality caregiving by the partner predicted the improvement of participants' mood from pre- to post-interaction. Although the researchers asked participants to rate adjectives indicative of negative affect, such as disappointment, they did not assess depressive symptoms specifically. In a second study, these researchers showed that less responsive caregiving was associated with greater avoidance of closeness (Feeney \& Collins, 2001). The third study relevant to this hypothesis examined the course of depression in a sample of clinically depressed married or cohabiting women (Whiffen et al., 2001). The extent to which husbands endorsed the dismissing prototype predicted their wives' depressive symptoms over a 6-month period. By definition, the dismissing prototype is associated with avoidance of closeness.

Another possible explanation for lack of responsiveness is genuine devaluation of the spouse. Devaluation may increase partner criticism and interfere with partners' ability to be supportive. Katz, Beach, and Joiner (1998) hypothesized that a romantic partner who is devaluing would increase depression levels particularly among individuals who tend to seek reassurance. They tested this hypothesis in a university sample of dating couples. They found that partner devaluation was not generally associated with increased depressed mood over a 6-week period. However, it was associated with increased depressed mood among individuals who tended to seek reassurance. Consistent with previous research (Davila, 2001), I propose that insecurely attached individuals will seek reassurance from their spouses.

To summarize, there is evidence that characteristics of the partner exacerbate depression levels over time. Specifically, partners who are poor caregivers, dismissing or avoidant in their attachment style, and devaluing have been shown to have an adverse impact on participants' mood. I hypothesize that these partner characteristics lead to perceptions of the partner as unresponsive to emotional needs and hence an unreliable attachment figure. The first goal of the present study was to test the hypotheses that (a) partner avoidance and devaluation are associated with spouses' perceptions of the partner as unresponsive to emotional needs and (b) spouses' perceptions of their partners as unresponsive are associated with attachment insecurity (see the left side of Figure 1).

Bowlby (1980) proposed that attachment insecurity contributes directly to the development of depressive symptoms. Two previous longitudinal studies examined the impact of attachment insecurity on depressive symptoms. Contrary to prediction, in both community samples of women, attachment insecurity did not predict depressive symptoms once initial symptom levels were controlled (Hammen et al., 1995; Whiffen et al., 2001). However, in the former study participants were young women who were not necessarily involved in dating or cohabiting relationships. Attachment insecurity in marital or cohabiting relationships should be particularly likely to lead to feelings of depression. In the latter study, the women already were depressed, which may have attenuated the association between attachment insecurity and depressive symptoms. Additionally, neither study evaluated this hypothesis in men. The second goal of the present study was to test the hypothesis that attachment insecurity leads to depression in a 


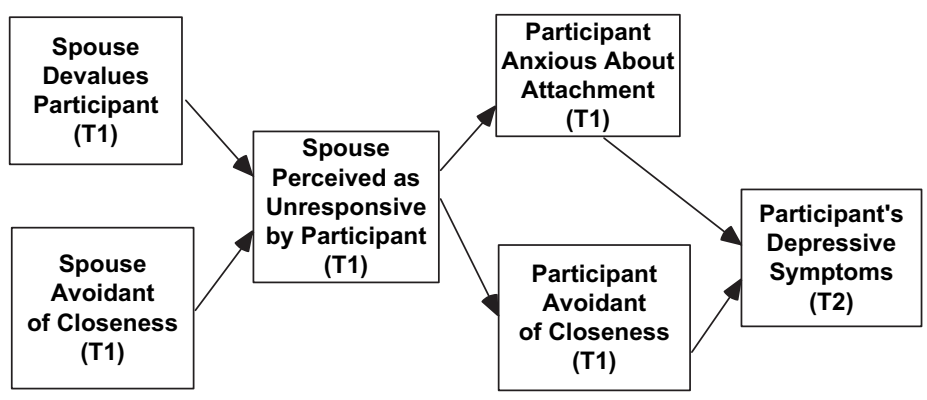

Figure 1. Theoretical model linking partner characteristics to participants' depressive symptoms through attachment insecurity.

sample of married or cohabiting men and women (see the right side of Figure 1).

The final goal was to evaluate the possibility that depressive symptoms have an adverse impact on attachment security. While most researchers assume that the causal arrow goes from attachment insecurity to depression, it is possible that negative feelings and perceptions associated with depression heighten fears about attachment figures. There is some evidence that depression and marital distress covary, such that changes in one variable are associated with parallel changes in the other (Karney, 2001). In the present study, I examined the possibility that depressed mood has an adverse impact on attachment security.

To summarize, I proposed an attachmenttheory model of depression in couples, which links characteristics of one partner to depression in the other. I hypothesized that individuals who are avoidant of closeness and/or who devalue their spouses will be unresponsive to their spouse when she/he expresses vulnerable emotions. Lack of responsiveness will increase the spouse's attachment insecurity, and over time, attachment insecurity will be associated with the development of depressive symptoms. This model was tested with longitudinal data collected over a 3-month period from a community sample of couples.

\section{Method}

\section{Participants and procedure}

A study Web site was set up that was linked to my university Web site. A notice about the study was submitted to the list managers of various Internet sites, newsgroups, and e-mail lists that were of interest to married or cohabiting couples with children. For instance, sites that provided parenting advice were approached. However, chat rooms were not used. List managers were asked for permission to post the notice for their members. Interested individuals were invited to visit the study Web site to read a detailed description of the study, including information about how the data they provided would be handled to ensure confidentiality. If they wished to participate, they were asked to provide their e-mail address to indicate informed consent. Once an address was entered, the participant was given access to the study questionnaires. When the questionnaires were completed, the participant clicked on the "submit" button, which sent the data to a secure server where it was downloaded into an SPSS file. Participants were reminded to close their browser, so their answers could not be viewed by others.

The research was described as a couples study, and participants were asked to invite their romantic partners or spouses to complete the questionnaires. Participants were asked to provide a unique password, such as the name of a family pet, so their responses could be paired. The e-mail addresses of individuals who completed all parts of the study were entered into a drawing for $\$ 100$.

With this procedure, 229 women and 149 men were recruited, with 136 couples providing data from both partners. On average, the participants were in their early to mid-30s and had been married or cohabiting with their partners for approximately 9 years. Almost $80 \%$ of the sample was married. Three quarters 
of the sample lived in the United States, with most of the remaining participants living in Canada or the United Kingdom. The couples had high levels of postsecondary education, and approximately half reported a family income greater than US\$45,000 per year. Husbands were typically employed. Wives were equally likely to be employed outside the home or engaged in unpaid work, such as being a student or looking after children.

Testing the proposed model required data from both partners at Time 1 (T1) and from at least one partner at Time 2 (T2) to assess changes in depressive symptoms and attachment security over time. Approximately 3 months after the initial contact, an e-mail message was sent to the 136 couples who completed questionnaires at $\mathrm{T} 1$, reminding them to return to the Web site and complete several of the questionnaires again. Thirteen e-mail addresses were no longer valid. Of the 257 individuals whose addresses were valid, 99 of the women ( $73 \%$ of T1 sample) and 82 of the men $(60 \%$ of the $\mathrm{T} 1$ sample) provided complete follow-up data at $\mathrm{T} 2$.

\section{Measures}

Center for Epidemiologic Studies Depression Scale, Revised. Depression was assessed with the Center for Epidemiologic Studies Depression Scale, Revised (CESD-R; Santor \& Coyne, 1997), which was originally developed as a measure of depressive symptoms in community samples of adults (Radloff, 1977). The revised scale consists of nine items, rated on a 4-point scale that ranges from rarely to most of the time. Participants indicate how often they experienced depressive symptoms during the past week. Santor and Coyne reported that the short version of the CESD has excellent internal consistency and correlates highly with total scores.

Experiences in Close Relationships. The Experiences in Close Relationships questionaire (ECR; Brennan et al., 1998) was used to measure the two dimensions underlying adult attachment: anxiety about rejection and avoidance of closeness. The ECR consists of 36 items, half of which measure each dimension.
Items are rated on a 7-point scale, ranging from disagree strongly to agree strongly. The anxiety scale assesses the extent to which individuals are concerned about abandonment and being unloved by romantic partners. The avoidance scale assesses the extent to which individuals are comfortable showing feelings and being close to romantic partners. The measure was developed using a large sample of undergraduate students, approximately half of whom were involved in a serious relationship at that time. Principal components analysis (PCA) confirmed the underlying twodimensional structure of the measure and produced scales with high alpha coefficients. The validity of the measure was demonstrated by replicating results that have been found in studies using categorical measures of attachment.

Rosenberg Partner Esteem Questionnaire. Devaluation of the partner was assessed using the partner version of the Rosenberg SelfEsteem Questionnaire (RSEQ; Rosenberg, 1965), which was developed by Swann, Wenzlaff, Krull, and Pelham (1992). The Rosenberg Partner Esteem Questionnaire consists of the 10 items from the RSEQ reworded so that participants complete it with regard to their spouses. A representative item is, "I feel that my partner has a number of good qualities." Each item is rated on a 5-point scale, ranging from strongly agree to strongly disagree. Scoring is reversed so that higher scores reflect a more negative view of the spouse. Previous research has shown the measure to have good internal consistency and to be predictive of depressed mood in conjunction with reassurance seeking (Katz et al., 1998).

\section{Relationship Expectations Questionnaire.} The extent to which individuals perceived their romantic partner or spouse to be responsive to the expression of a wide range of positive and negative emotions was measured with items developed for this study. The emotions of interest were vulnerability, love or tenderness, anger, depression or sadness, and neediness. Items were generated based on my clinical experience with couples using emotionally focused couple therapy (EFT; Johnson, 1996). EFT is an empirically validated intervention for 
couples (Johnson, Hunsley, Greenberg, \& Schindler, 1999) based on attachment theory. One of the primary goals of EFT is to increase attachment security by improving partners' responsiveness to one another's vulnerability.

The items sampled beliefs and fears about the partner as an attachment figure that distressed couples frequently report. A list of 40 potential items was generated that crossed five emotions with three possible partner responses. For instance, a responsive depression item was "If I told my partner that I felt sad, my partner would comfort me," while a rejecting depression item was "If I told my partner that I felt lonely, my partner would suggest that I call someone." All items were rated on a 5-point scale, ranging from strong disagreement that my partner would respond this way to strong agreement that my partner would respond this way.

PCA with Varimax rotation was used to reduce the 40 items to internally consistent and meaningful scales. Initially, the items were analyzed separately for males and females. However, this procedure produced highly similar results, so the analyses reported here are for the combined sample of 374 individuals, $40 \%$ of whom were male. Items were eliminated on an item-by-item basis if they loaded $<.30$ or on more than one factor. Reliability analyses also were conducted to identify items that contributed weakly to a factor or that were redundant with other items on the factor.

Inspection of the various solutions suggested that a 3-factor solution, which accounted for $47 \%$ of the variance, was the best fit to the data and produced scales comprising similar items. The first factor accounted for $34 \%$ of the variance, and the items suggested that it measured the extent to which the partner was perceived to be responsive to expressions of vulnerability, distress, and love (see Appendix). The alpha coefficients for this scale were .94 for the men and .93 for the women. The remaining factors were not predicted by attachment theory and are not discussed further here.

Perceived partner responsiveness was measured by summing participants' scores on the items. The distribution of scores on the resulting scale was skewed and kurtotic. The items were generated from clinical experiences with distressed couples, while the present sample was a nonclinical one with presumably average levels of marital satisfaction. Thus, many of the items may have received low levels of endorsement. Neither the skewness nor the kurtosis of the distribution could be modified with any of the transformations tried, so following from Tabachnick and Fidell (2001), the variable was dichotomized. All the analyses reported in this article were repeated using both the continuous measure of responsiveness and the dichotomized variable. The results were generally comparable but tended to be clearer and stronger with the dichotomized variable. Only the results with the dichotomized variable are reported for the remainder of this paper (Tabachnick \& Fidell).

In Table 1, the zero-order correlations among perceived responsiveness, attachment, and depressive symptoms are presented, separately

Table 1. Correlations among self-reports of perceived partner responsiveness, attachment, and depressive symptoms for individual participants at $T 1$

\begin{tabular}{lcccc}
\hline \hline & $\begin{array}{c}\text { Partner perceived } \\
\text { as responsive }\end{array}$ & $\begin{array}{c}\text { Avoidance of } \\
\text { closeness }\end{array}$ & $\begin{array}{c}\text { Attachment } \\
\text { anxiety }\end{array}$ & $\begin{array}{c}\text { Depressive } \\
\text { symptoms }\end{array}$ \\
\hline $\begin{array}{l}\text { Partner perceived as } \\
\text { responsive }\end{array}$ & 1.0 & $-.32^{* *}$ & $-.32^{* *}$ & $-.22^{* *}$ \\
$\begin{array}{l}\text { Avoidance of closeness } \\
\text { Attachment anxiety }\end{array}$ & $-.30^{* *}$ & 1.0 & .04 & .10 \\
Depressive symptoms & $-.42^{* *}$ & .05 & 1.0 & $.42^{* *}$ \\
\hline \hline
\end{tabular}

Note. Men's correlations are reported below the diagonal $(N=149)$; women's correlations are above the diagonal $(N=229)$.

$* p<.05 . * * p .01$. 
for the 149 men and 229 women who contributed data at T1. Consistent with attachment theory, perceptions of the partner as unresponsive were associated with self-reported attachment insecurity, both avoidance of closeness and attachment anxiety. In addition, lower levels of partner responsiveness were correlated with higher levels of self-reported depression for both men and women.

\section{Results}

\section{Characteristics of the couple sample}

The demographic data for the sample of couples at $\mathrm{T} 1$, along with the means and standard deviations for the study variables at $\mathrm{T} 1$ and $\mathrm{T} 2$, the alpha coefficients at $\mathrm{T} 1$ and $\mathrm{T} 2$, and the test-retest reliabilities are presented in Table 2. Demographically, the sample of couples was identical to the sample of individuals described earlier. Independent group $t$ tests showed that the married and cohabiting couples did not differ on any of the study variables measured at either assessment, so the groups were combined. For clarity, men and women are referred to as "husbands" and "wives," respectively.

Comparison of the wives who dropped out versus those who provided $\mathrm{T} 2$ data did not reveal any significant differences on the demographic or T1 study variables. However, com-

Table 2. Means and standard deviations for the demographic and study variables, alphas, and test-retest reliabilities for the sample of couples

\begin{tabular}{|c|c|c|c|c|c|c|c|}
\hline & \multicolumn{3}{|c|}{$\mathrm{T} 1$} & \multicolumn{3}{|c|}{$\mathrm{T} 2$} & \multirow[b]{2}{*}{ Test-Retest $r$} \\
\hline & $M$ & $S D$ & Alpha & $M$ & $S D$ & Alpha & \\
\hline \multicolumn{8}{|l|}{ Wives } \\
\hline \multicolumn{8}{|l|}{ Demographics } \\
\hline Age & 33.0 & 10.1 & & & & & \\
\hline Years married & 9.5 & 8.5 & & & & & \\
\hline Number of children & 1.7 & 1.5 & & & & & \\
\hline Family income $>\$ 45,000(\%)$ & 51.1 & & & & & & \\
\hline Post-secondary education (\%) & 85.4 & & & & & & \\
\hline Employed outside home (\%) & 45.6 & & & & & & \\
\hline \multicolumn{8}{|l|}{ Study variables } \\
\hline Depressive symptoms & 16.9 & 5.8 & .87 & 16.6 & 5.9 & .90 & .62 \\
\hline Attachment anxiety & 59.8 & 16.9 & .85 & 57.0 & 16.3 & .86 & .76 \\
\hline Avoidance of closeness & 46.5 & 16.4 & .85 & 48.0 & 18.1 & .93 & .73 \\
\hline Husband responsive to me & 42.3 & 9.4 & .94 & 42.9 & 8.0 & .91 & .44 \\
\hline My devaluation of husband ${ }^{\mathrm{a}}$ & 16.3 & 5.7 & .82 & & & & \\
\hline \multicolumn{8}{|l|}{ Husbands } \\
\hline \multicolumn{8}{|l|}{ Demographics } \\
\hline Age & 34.8 & 10.3 & & & & & \\
\hline Post-secondary education (\%) & 83.1 & & & & & & \\
\hline Employed outside home (\%) & 85.9 & & & & & & \\
\hline \multicolumn{8}{|l|}{ Study variables } \\
\hline Depressive symptoms & 16.4 & 5.6 & .86 & 15.6 & 5.0 & .84 & .58 \\
\hline Attachment anxiety & 58.0 & 15.3 & .84 & 58.4 & 14.7 & .80 & .78 \\
\hline Avoidance of closeness & 51.2 & 14.6 & .80 & 51.2 & 14.6 & .91 & .71 \\
\hline Wife responsive to me & 41.8 & 9.5 & .95 & 40.4 & 9.7 & .94 & .42 \\
\hline My devaluation of wife ${ }^{a}$ & 16.4 & 6.3 & .85 & & & & \\
\hline
\end{tabular}

Note. $N=136$ couples at T1. $N=99$ women and 82 men at $\mathrm{T} 2$.

${ }^{\mathrm{a}}$ Devaluation data were collected at $\mathrm{T} 1$ only. 
parison of the husbands who dropped out versus those who provided T2 data showed a number of differences. The husbands who completed the T2 measures had reported at $\mathrm{T} 1$ that they were more avoidant of attachment figures, $t(133)=2.02, p<.05$, more devaluing of their wives, $t(133)=2.24, p<.05$, and that they perceived their wives as less responsive to them, $t(133)=3.48, p<.01$, than did the husbands who dropped out of the study. Thus, the men who continued in the study appear to have been more distressed about their marriages at $\mathrm{T} 1$ than were the men who dropped out.

Comparisons within couples with paired sample $t$ tests indicated that the husbands reported more avoidance at $\mathrm{T} 1$ than did their wives, $t(134)=2.45, p<.05$. No other within-couple differences were significant at $\mathrm{T} 1$ or $\mathrm{T} 2$.

\section{Do avoidance of closeness and partner devaluation predict perceived unresponsiveness?}

I hypothesized that self-reported avoidance of closeness and devaluation of the spouse would be associated with spouses' perceptions of their partners as unresponsive (see Figure 1). This hypothesis was tested with the data provided by the sample of 136 couples at $\mathrm{T} 1$. Inspection of the zero-order correlations reported in Table 3 showed that, as predicted, women who perceived their husbands as less responsive to their expressed vulnerability were married to men who rated themselves as more avoidant of closeness. Husbands' self-reported devaluation of their wives was not associated with their wives' perceptions of them as unresponsive.

Among the men, perceptions of their wives' responsiveness were associated both with the wives' self-reported avoidance of closeness and the wives' devaluation of their husbands. Wives' avoidance and devaluation of their husbands were correlated ( $r=.52)$, so the variables were entered simultaneously into a multiple regression equation to predict husbands' perceptions of wives' responsiveness. This equation was significant, $F(2,132)=7.32$, $p<.01$, and accounted for $10 \%$ of the variance in husbands' perceptions of their wives' responsiveness. Inspection of the $t$ values showed that only wives' avoidance was uniquely associated with husbands' perceptions of their responsiveness $(\beta=-.29, p<.01)$; wives' devaluation of their husbands did not make a significant contribution with both variables in the equation $(\beta=-.06, p>.10)$. Thus, husbands' perceptions of their wives as unresponsive were associated with their wives' self-reported avoidance of closeness.

Interestingly, unresponsiveness did not reflect genuine devaluation of the spouse, except that devaluation covaried with avoidance of closeness. As a result of these analyses, the proposed model was modified by omitting devaluation of the partner as a variable.

\section{Test of the model}

Prediction of the husbands' depressive symptoms at T2. The zero-order correlations among the variables in the model are presented for husbands in Table 4. Inspection of these correlations showed that husbands' $\mathrm{T} 2$ depressive

Table 3. Correlations between participants' perceptions of partner responsiveness and their spouses' self-reported attachment and devaluation of them at T1

\begin{tabular}{lcc}
\hline \hline & $\begin{array}{c}\text { Husband perceived } \\
\text { as responsive }\end{array}$ & $\begin{array}{c}\text { Wife perceived } \\
\text { as responsive }\end{array}$ \\
\hline Spouse avoidance of closeness & $-.29^{* *}$ & $-.31^{* *}$ \\
Spouse attachment anxiety & -.15 & .05 \\
Spouse devaluation of partner & -.07 & $-.19^{*}$ \\
\hline \hline
\end{tabular}




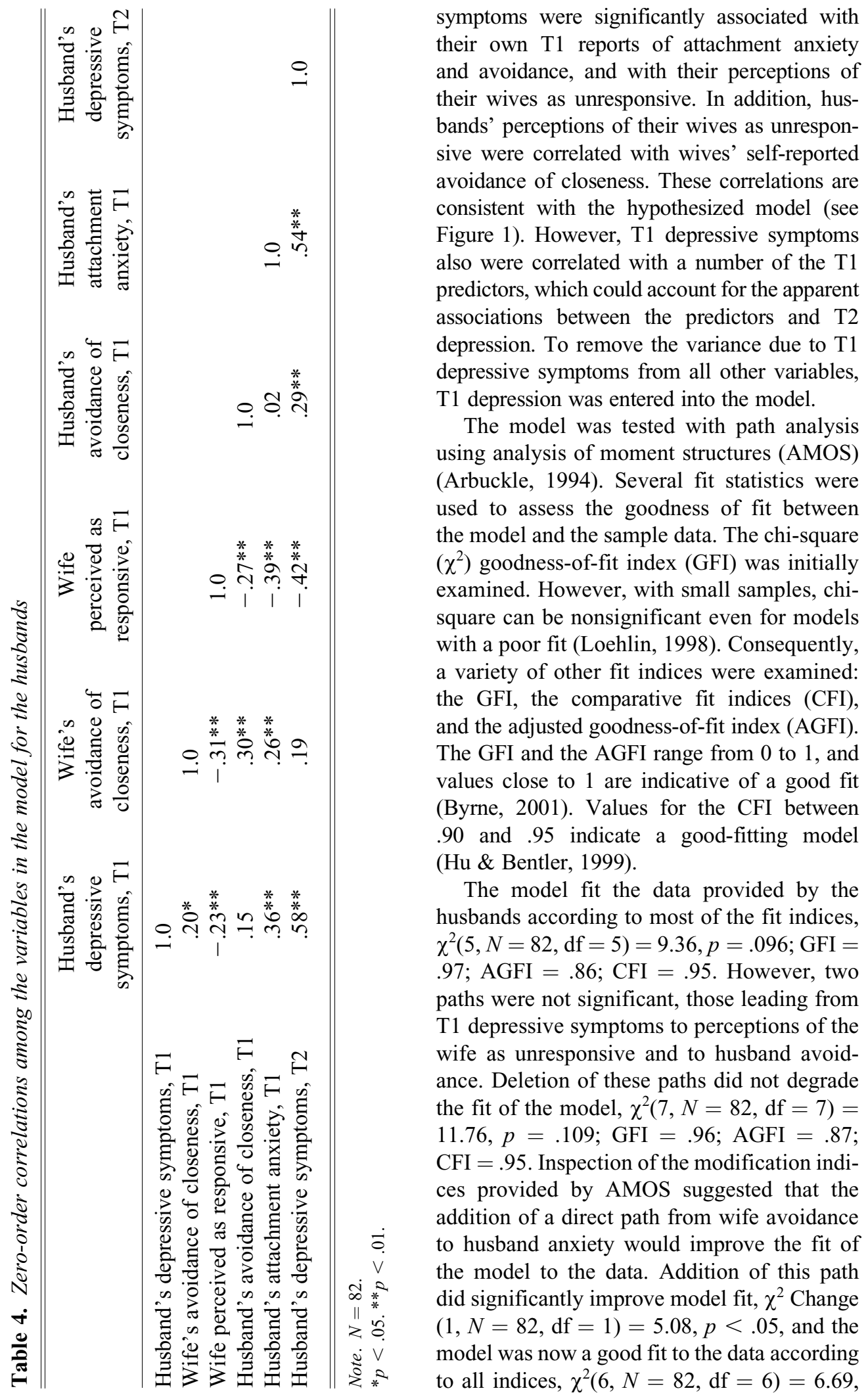


$p=.351 ; \mathrm{GFI}=.97$; AGFI $=.91 ; \mathrm{CFI}=.99$. In total, the predictors accounted for $49.8 \%$ of the variance in husbands' T2 depressive symptoms.

The final model with standardized path coefficients is illustrated in Figure 2. Only statistically significant paths $(p<.05)$ are identified. Husbands who were more depressed at $\mathrm{T} 1$ also were more anxious about attachment figures. Interestingly, their wives reported being more avoidant of closeness. Once T1 depression levels were controlled, wives who were more avoidant of closeness were perceived by their husbands as less responsive to the husbands' emotional needs, which was associated with higher levels of husbands' attachment insecurity at T1. In addition, wives' avoidance was associated directly with higher levels of husband attachment anxiety. Husbands' T1 attachment insecurity, both avoidance of closeness and anxiety, predicted their depressive symptoms at $\mathrm{T} 2$.

Prediction of wives' depressive symptoms at T2. Inspection of the zero-order correlations showed that, as predicted, wives' T2 depressive symptoms were correlated with their attachment anxiety and their perceptions of their husbands as unresponsive to them at $\mathrm{T} 1$ (see Table 5). In addition, wives' perceptions of their husbands as unresponsive were associated with husbands' self-reported avoidance of closeness. These correlations are consistent with the proposed model. However, T1 depressive symptoms were associated with several of the $\mathrm{T} 1$ predictors and could account for these associations. Therefore, the model was tested while controlling for the effect of T1 depression on all other variables.

Path analysis showed that the model fit the women's data according to some indexes, $\chi^{2}(5, N=99, \mathrm{df}=5)=10.53, p=.061 ;$ $\mathrm{GFI}=.97$; $\mathrm{AGFI}=.87$; $\mathrm{CFI}=.94$. However, several paths were not significant. Women's depressive symptoms at $\mathrm{T} 1$ were not associated with their own or their husbands' avoidance of closeness, or their perceptions of their husbands as unresponsive. In addition, perceptions of the husband as unresponsive were not associated with $\mathrm{T} 1$ attachment anxiety. Finally, wives' T1 attachment insecurity did not predict their T2 depressive symptoms.

The six nonsignificant paths were deleted, which did not degrade the fit of the model. Although the final model was a good fit to the data according to all indices, $\chi^{2}(11, N=99$, $\mathrm{df}=11)=14.65, p=.101 ; \mathrm{GFI}=.96$; $\mathrm{AGFI}=.90 ; \mathrm{CFI}=.94$, only a portion of the

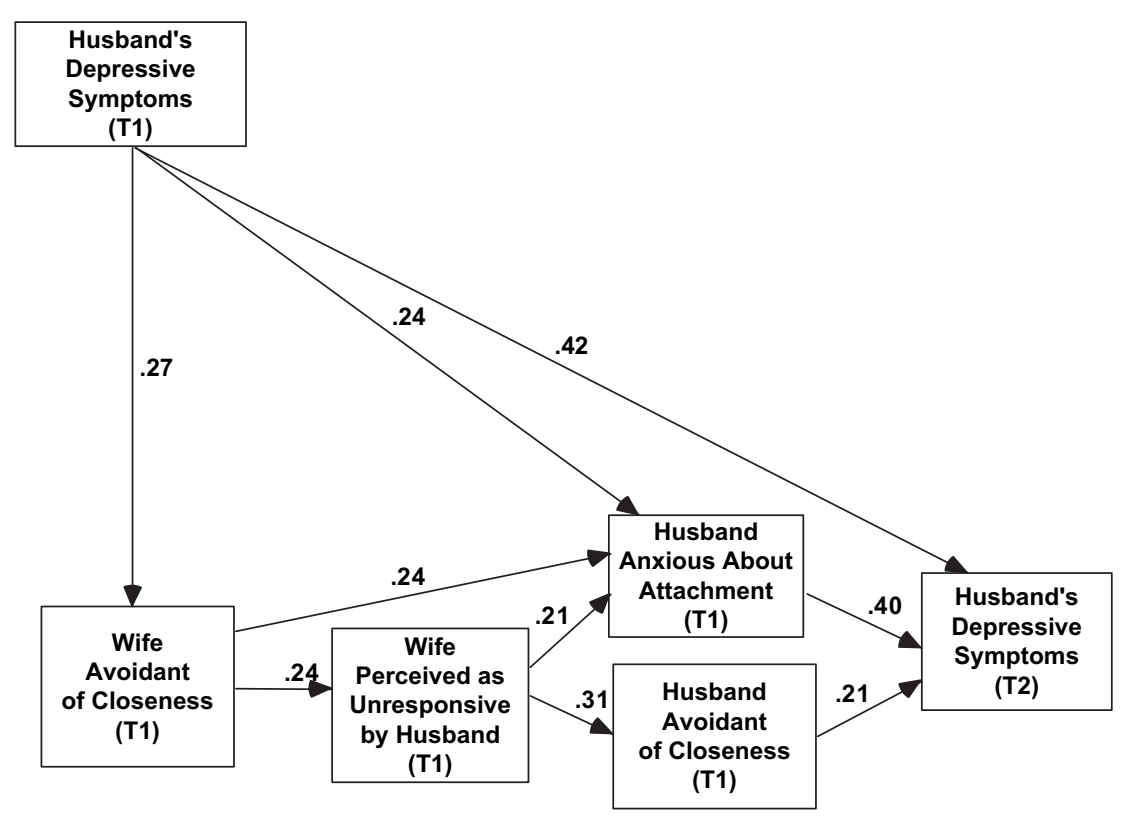

Figure 2. Final model for the husbands. 


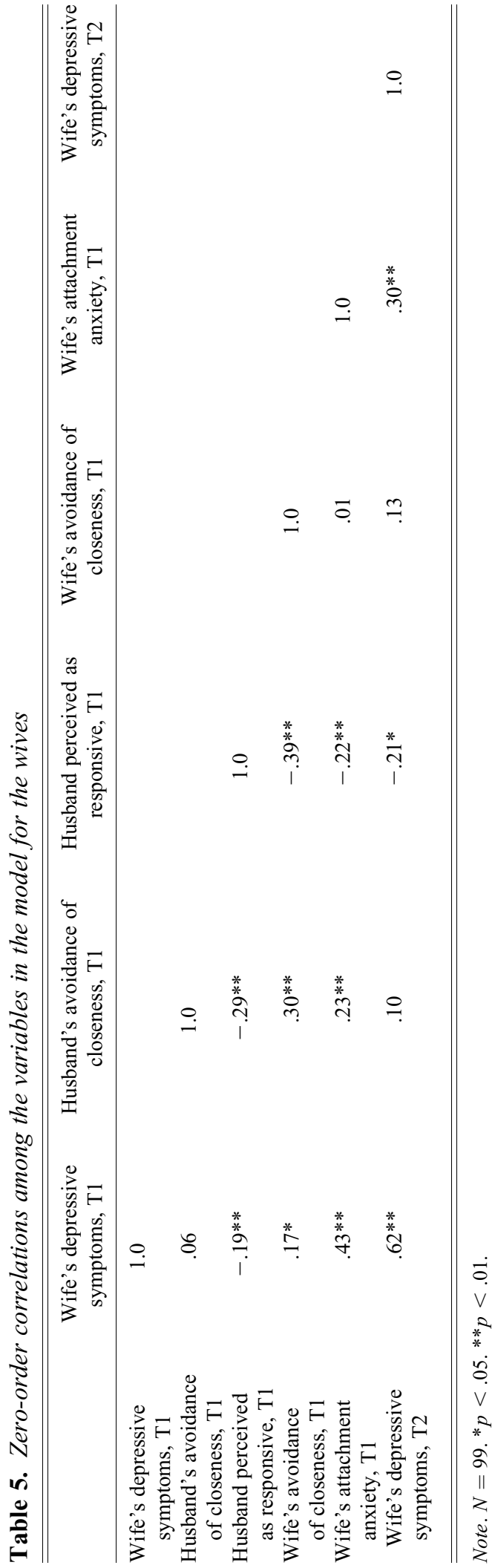

theoretical model was supported (see Figure 3). Consistent with the proposed model, husbands who reported that they were avoidant of closeness were perceived by their wives as unresponsive to vulnerability, and these women reported that they were more avoidant of closeness. Thus, the significant zero-order correlation between husbands' and wives' avoidance was accounted for by wives' perceptions of their husbands as unresponsive to vulnerability. The top half of this figure shows that women who were more depressed at $\mathrm{T} 1$ also were more anxious about attachment figures at T1. However, contrary to the theoretical model, attachment insecurity at $\mathrm{T} 1 \mathrm{did}$ not predict depressive symptoms at $\mathrm{T} 2$. In total, the predictors accounted for $38.7 \%$ of the variance in wives' $\mathrm{T} 2$ depression.

Do $T 1$ depressive symptoms predict T2 attachment insecurity? A secondary goal of this study was to evaluate the possibility that depression has an impact on attachment insecurity. This hypothesis was tested by constructing four hierarchical multiple regression equations to predict T2 avoidance of closeness and attachment anxiety from $\mathrm{T} 1$ depression, separately for husbands and wives. In all cases, T1 scores on the criterion were entered first to control for initial levels of attachment insecurity. For both husbands and wives, T2 avoidance of closeness was predicted only by $\mathrm{T} 1$ avoidance. The addition of $\mathrm{T} 1$ depression after initial levels of avoidance were controlled did not add significantly to the equation, $F$ Change $(1,79)=2.18$, $p>.05$ for husbands; $F$ Change $(1,96)=1.17$, $p>.05$ for wives. However, for both husbands and wives, there were trends for $\mathrm{T} 1$ depression to make a significant contribution to T2 anxiety even after T1 anxiety was controlled, $F$ Change $(1,79)=3.60, p<.10$ for husbands; $F$ Change $(1,96)=3.58, p<.10$ for wives. Thus, there was a nonsignificant tendency for more depressed persons at $\mathrm{T} 1$ to be more anxious about attachment figures at $\mathrm{T} 2$.

\section{Discussion}

The primary goal of the present study was to evaluate an attachment-theory model of depression in couples, which links the characteristics 


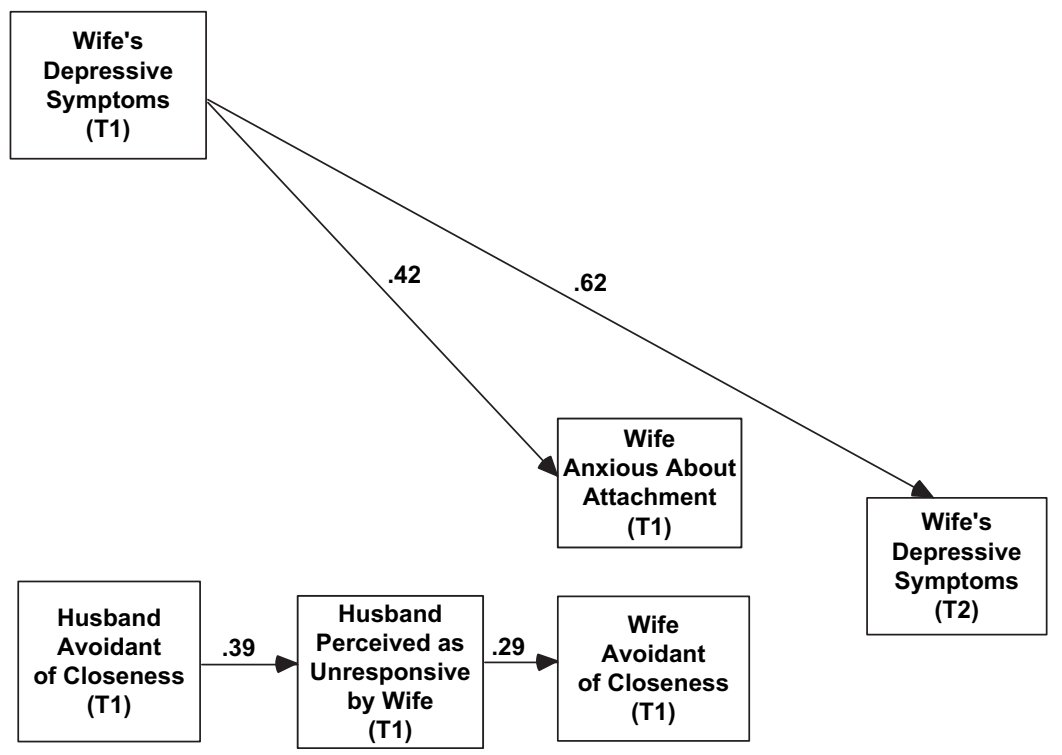

Figure 3. Final model for the wives.

of one partner to attachment insecurity and depression in the other partner. I hypothesized that one partner's avoidance of closeness and devaluation of the spouse would be linked to the other partner's perception of him/her as unresponsive to emotional needs. Perceived lack of responsiveness was suggested to lead to attachment insecurity and depressive symptoms.

The part of the model that was supported for both husbands and wives was the link between one partner's avoidance of closeness and the other partner's attachment insecurity. Wives' avoidance of closeness was associated with both dimensions of husbands' attachment security, while husbands' avoidance of closeness was associated with their wives' avoidance. Thus, for both husbands and wives, people who felt more insecure about attachment figures were married to individuals who rated themselves as avoidant of closeness. This finding is particularly compelling because there was no shared method variance to inflate the statistical association between the variables.

Also consistent with the proposed model, this link was explained at least in part by the perception that the avoidant partner was unresponsive to expressions of vulnerability. Avoidant partners were seen to reject or ignore their spouses' bids for emotional contact. Given that the partners described themselves as avoidant of closeness, we can be confident that their spouses' perceptions of them as unresponsive are grounded in real interactions. Avoidant persons' discomfort with vulnerable feelings, lack of attunement to feelings, and inadequate provision of support and care (Campbell et al., 2001; Feeney \& Collins, 2001; Fraley \& Shaver, 1998; Mikulincer et al., 1993) probably lead to their being perceived as unresponsive to their spouses' emotional needs. The results of the present study demonstrate that when one partner expresses vulnerable feelings and the other person does not respond appropriately, the vulnerable person is likely to feel more insecure about attachment figures. This insecurity appears to be a realistic response to the characteristics of avoidant partners.

Perceived unresponsiveness fully mediated the association between husbands' avoidance and wives' avoidance. However, in the husbands' model, an additional path was suggested directly from wives' avoidance to husbands' anxiety about attachment figures. Thus, women who are avoidant of closeness contribute to their husbands' attachment anxiety in ways that are unrelated to perceived unresponsiveness. Another possible mediator is the inference that 
the husband makes about the source of his wife's avoidance. Normatively, women are the caretakers of romantic relationships. Women report using relationship maintenance strategies more than their husbands do (Ragsdale, 1996), and they create more intimate relationships than do men (Dindia \& Allen, 1992). Compared with men, women are more likely to provide emotional support (Barbee et al., 1993) and to comfort others (Kunkel \& Burleson, 1999). Thus, avoidance of closeness and lack of responsiveness to vulnerability are counter-normative among women. Men likely expect their wives to seek intimacy and to provide nurturance and support to them, and they may question how much their wives love them when their wives do not enact these behaviors in the marriage. Men who are married to unresponsive women may fear that their wives' lack of responsiveness reflects a lack of love and care, which may increase their fears about rejection and abandonment.

In clinical practice, individuals often infer that their unresponsive spouses do not love or care for them. Because this inference is so common, in the present study, I attempted to assess lack of love with a measure of partner devaluation. The items on this questionnaire measure how highly a person regards his or her spouse. Contrary to the proposed model and to the inference made by many distressed couples, individuals who were perceived as unresponsive to their spouses' vulnerability did not genuinely devalue their spouses. Instead, their lack of responsiveness reflected their own discomfort with closeness. Interestingly, this result confirms what EFT therapists have always assumed: Individuals who are unresponsive to their partners' vulnerability do not genuinely devalue their partners. Replacing this inference with a more benign one is one of the major tasks of EFT (Johnson, 1996). For instance, the EFT therapist may reframe the spouse's unresponsiveness as helplessness because he/she does not know how to provide comfort. The present study provides empirical support for this intervention.

Gender differences may help us understand why husbands' avoidance and unresponsiveness was associated with their wives' increased avoidance but not with their greater anxiety about attachment figures. Women who are married to unresponsive men may realize that there is little point in disclosing feelings of vulnerability to a husband who will not respond appropriately. However, they may be less inclined than men are to infer that their unresponsive spouses do not love them. Compared with women, men are perceived to be less sensitive and less effective at providing comfort, and both sexes prefer to receive comfort from women (Kunkel \& Burleson, 1999). Thus, it may be relatively easy for a woman who is married to an unresponsive man to attribute his behavior to gender rather than lack of love. This attribution could protect them from becoming anxious about rejection or abandonment.

The second part of the proposed model linked attachment insecurity to the exacerbation of depressive symptoms over time. This part of the model was supported only by the husbands' data. Married or cohabiting men who were uncomfortable with closeness and/ or who feared that they would be rejected or abandoned were at risk for developing depressive symptoms over a relatively short period of time. This finding is consistent with previous cross-sectional studies of married or cohabiting men (Davila, Bradbury, \& Fincham, 1998, Study 2; Oliver \& Whiffen, 2003), and this is the first study to demonstrate prospectively that attachment insecurity is involved in the exacerbation of married men's depressive symptoms. These data clearly demonstrate the utility of this model as a way of understanding depression that occurs in married or cohabiting men.

In contrast, attachment insecurity did not contribute to women's depressive symptoms once baseline levels of depression were controlled. Two previous longitudinal studies also produced null results, one in a sample of young women who were not necessarily in a romantic relationship (Hammen et al., 1995) and one in a sample of clinically depressed women (Whiffen et al., 2001). The present study extends previous research by showing that attachment insecurity does not lead directly to depression even in a nonclinical sample of married or cohabiting women. One possible explanation for the null result is that women who are insecurely attached to their husbands find other sources of 
emotional support. In contrast, insecurely attached husbands may have few sources of emotional support outside of their marriages, which may explain their greater vulnerability to depression when the marital relationship is insecure.

The final noteworthy aspect of the men's results is that husbands' depressive symptoms at T1 were associated with their wives' avoidance of closeness. According to the model, wives' avoidance then exacerbates husbands' depressive symptoms through an impact on attachment insecurity. A similar process was not evident in the results for the women. Many of the items on the avoidance of closeness subscale refer to sharing problems and feelings with the partner. Thus, one possible explanation for this finding is that women who are married to depressed men keep things to themselves to avoid upsetting their husbands. This could be seen as a form of caretaking. Alternatively, wives' avoidance of closeness may be a form of rejection. Interaction partners are known to reject depressed persons, particularly by avoiding contact with them (Segrin \& Dillard, 1992). The final possibility is that depression, which increases one's self-focus, impairs the husband's ability to be an active and helpful listener, so his wife stops confiding in him. Whatever the reason for this result, it suggests the presence of a pernicious feedback loop that may make married men's depression particularly resistant to change.

While the association of depression with marital distress is well recognized among women, researchers and clinicians have not highlighted the role of marital relations in men's depression. Couple therapy would appear to be a useful adjunct to or substitute for individual therapy in the treatment of men's depression. Previous research has shown the utility of couple therapy for the treatment of women's depression (Jacobson, Dobson, Fruzzetti, Schmaling, \& Salusky, 1991). Furthermore, the results of the present study indicate that couple therapy focused on the repair of damaged attachment bonds, such as EFT (Johnson, 1996), may be an effective treatment for men's depression.

Interestingly, there was little evidence that depressive symptoms erode attachment security. There was a nonsignificant tendency for more depressed individuals at $\mathrm{T} 1$ to report in- creased anxiety about attachment figures at $\mathrm{T} 2$. This correlation may be significant in a larger sample or in a clinical sample, where the association between marital distress and depression tends to be stronger (Whisman, 2001). The impact of depressive symptoms on attachment also might be more apparent over a longer period of time. Couples who have been married or cohabiting for nearly 10 years on average are likely to have stable perceptions of their partners. When there is little change in the criterion, predictors have nothing to predict. Indeed, the attachment ratings of these couples were very stable over the 3-month period of the study. The possibility that depression has an impact on attachment security should be explored further in research with a larger sample to detect a smaller effect and longer time frame over which more changes in the criterion may occur.

Two distinct lines of research have examined adult attachment processes. The first tradition is that adopted in the present article; the second follows from the work of Mary Main and her colleagues (Main, Kaplan, \& Cassidy, 1985) and assesses adults' "current state of mind" with respect to their early relationships with parents. Main is interested less in whether or not early attachment relationships were secure than in whether an individual can provide a coherent description of his/her past attachment relationships. It may be important to consider participants' early attachment history, as well as their adult attachment security, when attempting to predict the onset or exacerbation of depressive symptoms. This hypothesis is consistent with Bowlby's (1980) original formulation, as well as with a large literature indicating that adult depression is associated with perceptions of parents as having been cold and rejecting during childhood (Brewin, Andrews, \& Gotlib, 1993). There is some evidence that perceived parental rejection increases concerns about rejection by romantic partners and contributes to feelings of depression (Oliver \& Whiffen, 2003). Thus, an important modification to the model would include a role for the current state of mind about early attachment relationships.

The present study is limited methodologically by the sample and the use of self-reports. First, the men who continued in the study were 
more distressed about their marriages than were the men who dropped out. Their selfselection into the longitudinal portion of the study may have strengthened the association between attachment insecurity and depressive symptoms for the men in the sample. In addition, this sample of couples was not distressed. The results may not generalize to samples of clinically depressed individuals where the range of attachment security may be more restricted. In addition, the sample tended to be highly educated, and all participants had access to a computer. Although the results of online studies across a variety of research areas have produced results that are indistinguishable from those produced by traditional pencil and paper methods (e.g., Krantz, Ballard, \& Scher, 1997), it would be important to replicate these findings in a sample of couples where a broader range of socioeconomic status was represented.

Finally, self-reports were used to assess all the study variables. Observational studies of couples' interactions would confirm selfreports and may provide a richer picture of the role that these variables play in the development of depression. While self-reports are widely used to measure depressive symptoms, they do not measure clinical depression, which may differ from elevated symptom levels in important ways (Coyne, 1994). Despite these limitations, this study is an important step in articulating the links among avoidance of closeness, attachment insecurity, and depression in couples.

\section{References}

Anderson, P., Beach, S. R. H., \& Kaslow, N. J. (1999). Marital discord and depression: The potential of attachment theory to guide integrative clinical intervention. In T. Joiner \& J. C. Coyne (Eds.), The interactional nature of depression (pp. 271-297). Washington, DC: American Psychological Association.

Arbuckle, J. L. (1994). AMOS: Analysis of moment structures. Psychometrika, 59, 135-137.

Baldwin, M. W. (1992). Relational schemas and the processing of social information. Psychological Bulletin, $112,461-484$.

Barbee, A. P., Cunningham, M. R., Winstead, B. A., Derlega, V., Gulley, M. R., Yankeelov, A., et al. (1993). Effects of gender role expectations on social support process. Journal of Social Issues, 49, 175-190.
Bartholomew, K. (1990). Avoidance of intimacy: An attachment perspective. Journal of Personal and Social Relationships, 7, 147-178.

Bowlby, J. (1969). Attachment and loss Vol. 1: Attachment. New York: Basic Books.

Bowlby, J. (1973). Attachment and loss Vol. 2: Separation, anxiety, and anger. New York: Basic Books.

Bowlby, J. (1980). Attachment and loss Vol. 3: Loss. New York: Basic Books.

Brennan, K. A., Clark, C. C., \& Shaver, P. R. (1998). Self report measurement of adult attachment. In J. A. Simpson \& W. S. Rholes (Eds.), Attachment theory and close relationships (pp. 46-76). New York: Guilford.

Brewin, C. R., Andrews, B., \& Gotlib, I. H. (1993). Psychopathology and early experience: A reappraisal of retrospective reports. Psychological Bulletin, 113, 82-98.

Byrne, B. M. (2001). Structural equation modeling with AMOS: Basic concepts, applications, and programming. Mahwah, NJ: Lawrence Erlbaum.

Campbell, L., Simpson, J. A., Kashy, D. A., \& Rholes, W. S. (2001). Attachment orientations, dependence, and behavior in a stressful situation: An application of the Actor-Partner Interdependence Model. Journal of Social and Personal Relationships, 18, 821-843.

Carnelley, K. B., Pietromonaco, P. R., \& Jaffe, K. (1994). Depression, working models of others, and relationship functioning. Journal of Personality and Social Psychology, 66, 127-140.

Collins, N. L., \& Feeney, B. C. (2000). A safe haven: An attachment theory perspective on support seeking and caregiving in intimate relationships. Journal of Personality and Social Psychology, 78, 1053-1073.

Coyne, J. C. (1994). Self-reported distress: Analog or ersatz depression? Psychological Bulletin, 116, 29-45.

Cyranowski, J. M., Bookwala, J., Feske, U., Houck, P., Pilkonis, P., Kostelnik, B., et al. (2002). Adult attachment profiles, interpersonal difficulties, and response to interpersonal psychotherapy in women with recurrent major depression. Journal of Social and Clinical Psychology, 21, 191-217.

Davila, J. (2001). Refining the association between excessive reassurance seeking and depressive symptoms: The role of related interpersonal constructs. Journal of Social and Clinical Psychology, 20, 538-559.

Davila, J., Bradbury, T. N., \& Fincham, F. (1998). Negative affectivity as a mediator of the association between adult attachment and marital satisfaction. Personal Relationships, 5, 467-484.

Dindia, K., \& Allen, M. (1992). Sex differences in selfdisclosure: A meta-analysis. Psychological Bulletin, $112,106-124$.

Feeney, B. C., \& Collins, N. L. (2001). Predictors of caregiving in adult intimate relationships: An attachment theoretical perspective. Journal of Personality and Social Psychology, 80, 972-994.

Fraley, R. C., \& Shaver, P. R. (1998). Airport separations: A naturalistic study of adult attachment dynamics in separating couples. Journal of Personality and Social Psychology, 75, 1198-1212.

Griffin, D., \& Bartholomew, K. (1994a). Models of the self and other: Fundamental dimensions underlying measures of adult attachment. Journal of Personality and Social Psychology, 67, 430-445.

Haaga, D. A., Yarmus, M., Hubbard, S., Brody, C., Solomon, A., Kirk, L., et al. (2002). Mood dependency of self-rated attachment style. Cognitive Therapy and Research, 26, 57-71. 
Hammen, C. L., Burge, D., Daley, S. E., Davila, J., Paley, B., \& Rudolph, K. D. (1995). Interpersonal attachment cognitions and prediction of symptomatic responses to interpersonal stress. Journal of Abnormal Psychology, 104, 436-443.

Hazan, C., \& Shaver, P. (1987). Romantic love conceptualized as an attachment process. Journal of Personality and Social Psychology, 52, 511-524.

Hooley, J. M., \& Teasdale, J. D. (1989). Predictors of relapse in unipolar depressives: Expressed emotion, marital distress, and perceived criticism. Journal of Abnormal Psychology, 98, 229-235.

Hu, L.-T., \& Bentler, P. M. (1999). Cutoff criteria for fit indexes in covariance structure analysis: Conventional criteria versus new alternatives. Structural Equation Modeling: A Multidisciplinary Journal, 6, 1-55.

Ingram, R. E., Miranda, J., \& Segal, Z. V. (1998). Cognitive vulnerability to depression. New York: Guilford.

Jacobson, N. S., Dobson, K., Fruzzetti, A. E., Schmaling, K. B., \& Salusky, S. (1991). Marital therapy as a treatment for depression. Journal of Consulting and Clinical Psychology, 59, 547-557.

Johnson, S. M. (1996). The practice of emotionally focused marital therapy: Creating connection. New York: Brunner/Mazel.

Johnson, S. M., Hunsley, J., Greenberg, L., \& Schindler, D. (1999). Emotionally focused couples therapy: Status and challenges. Clinical Psychology: Science \& Practice, 6, 67-79.

Johnson, S. M., \& Whiffen, V. E. (1999). Made to measure: Adapting emotionally focused couples therapy to partners' attachment styles. Clinical Psychology: Science \& Practice, 6, 366-381.

Johnson, S. M., \& Whiffen, V. E. (2003). Attachment processes in couple and family therapy. New York: Guilford.

Karney, B. R. (2001). Depressive symptoms and marital satisfaction in the early years of marriage: Narrowing the gap between theory and research. In S. R. H. Beach (Ed.), Marital and family processes in depression (pp. 45-68). Washington, DC: American Psychological Association.

Katz, J., Beach, S. R. H., \& Joiner, T. E. (1998). When does partner devaluation predict emotional distress? Prospective moderating effects of reassurance-seeking and self-esteem. Personal Relationships, 5, 409-421.

Kobak, R. R., \& Hazan, C. (1991). Attachment in marriage: Effects of security and accuracy of working models. Journal of Personality and Social Psychology, 60, 861-869.

Krantz, J., Ballard, J., \& Scher, J. (1997). Comparing the results of laboratory and World Wide Web samples on the determinants of female attractiveness. Behaviour Research Methods, Instruments, and Computers, 29 , 264-269.

Kunkel, A. W., \& Burleson, B. R. (1999). Assessing explanations for sex differences in emotional support: A test of the different cultures and skill specialization accounts. Human Communication Research, 25, 307-340.

Loehlin, J. C. (1998). An introduction to factor, path, and structural analysis. Mahwah, NJ: Lawrence Erlbaum.

Main, M., Kaplan, N., \& Cassidy, J. (1985). Security in infancy, childhood, and adulthood: A move to the level of representation. Monographs of the Society for Research in Child Development, 50, 66-104.

Mikulincer, M. (1998). Adult attachment style and individual differences in functional versus dysfunctional experiences of anger. Journal of Personality and Social Psychology, 74, 513-524.

Mikulincer, M., Florian, V., \& Weller, A. (1993). Attachment styles, coping strategies, and post-traumatic psychological distress: The impact of the Gulf War in Israel. Journal of Personality and Social Psychology, 64, 817-826.

Oliver, L. E., \& Whiffen, V. E. (2003). Perceptions of parents and partners and men's depressive symptoms. Journal of Social and Personal Relationships, 20, 621-635.

Radloff, L. S. (1977). The CES-D Scale: A self-report depression scale for research in the general population. Applied Psychological Measurement, 1, 385-401.

Ragsdale, J. D. (1996). Gender, satisfaction level and the use of relational maintenance strategies in marriage. Communication Monographs, 63, 354-369.

Roberts, J. E., Gotlib, I. H., \& Kassel, J. (1996). Adult attachment security and symptoms of depression: The mediating roles of dysfunctional attitudes and low self-esteem. Journal of Personality and Social Psychology, 70, 310-320.

Rosenberg, M. (1965). Society and adolescent self-image. Princeton, NJ: Princeton University.

Santor, D. A., \& Coyne, J. C. (1997). Shortening the CES-D to improve its ability to detect cases of depression. Psychological Assessment, 9, 233-243.

Scott, R. L., \& Cordova, J. V. (2002). The influence of adult attachment styles on the association between marital adjustment and depressive symptoms. Journal of Family Psychology, 16, 199-208.

Segrin, C., \& Dillard, J. P. (1992). The interactional theory of depression: A meta-analysis of the research literature. Journal of Social and Clinical Psychology, 11, 43-70.

Simpson, J. A. (1990). Influence of attachment styles on romantic relationships. Journal of Personality and Social Psychology, 59, 971-980.

Simpson, J. A., Rholes, W. S., \& Nelligan, J. S. (1992). Support seeking and support giving within couples in an anxiety-provoking situation: The role of attachment styles. Journal of Personality and Social Psychology, $62,434-446$.

Simpson, J. A., Rholes, W. S., \& Phillips, D. (1996). Conflict in close relationships: An attachment perspective. Journal of Personality and Social Psychology, 71, 899-914.

Swann, W. B., Wenzlaff, R. M., Krull, D. S., \& Pelham, B. W. (1992). Allure of negative feedback: Selfverification strivings among depressed persons. Journal of Abnormal Psychology, 101, 293-306.

Tabachnick, B., \& Fidell, L. S. (2001). Using multivariate statistics. Boston: Allyn \& Bacon.

Whiffen, V. E., \& Johnson, S. M. (1998). An attachment theory framework for the treatment of childbearing depression. Clinical Psychology: Science \& Practice, $5,478-493$.

Whiffen, V. E., Kallos-Lilly, A. V., \& MacDonald, B. J. (2001). Depression and attachment in couples. Cognitive Therapy and Research, 25, 577-590.

Whisman, M. A. (2001). The association between depression and marital dissatisfaction. In S. R. H. Beach (Ed.), Marital and family processes in depression (pp. 3-24). Washington, DC: American Psychological Association.

Whisman, M. A., \& Bruce, M. L. (1999). Marital dissatisfaction and incidence of major depressive episode in a community sample. Journal of Abnormal Psychology, 108, 674-678. 


\section{Appendix}

Final items on the responsiveness to vulnerability measure

1. If I told my partner that I loved him/her, my partner would tell me that she/he loves me too.

2. If I told my partner something very personal about myself, my partner would treat me tenderly.

3. If I told my partner that I felt unsure of myself, my partner would express confidence in me.

4. If I asked my partner to comfort me, my partner would be embarrassed. (R)
5. If I expressed tender feelings for my partner, my partner would be uncomfortable. (R)

6. If I were upset, my partner would ask me what was wrong.

7. If I planned a romantic evening at home with my partner, my partner would say that he/she would prefer to go out. (R)

8. If I told my partner how I really felt, my partner would respect my feelings.

9. If I seemed down, my partner would pretend nothing was wrong. $(\mathrm{R})$

10. If I told my partner that I needed him/ her, my partner would be confused. (R) 